\title{
Birth outcomes in the Inuit-inhabited areas of Canada
}

\author{
Zhong-Cheng Luo MD PhD, Sacha Senécal PhD, Fabienne Simonet MS, Éric Guimond PhD, \\ Christopher Penney MA, Russell Wilkins MUrb
}

Previously published at www.cmaj.ca

$\infty \quad$ See related research article by Egeland and colleagues, page 243, and related commentary by Cunningham, page 228

\section{ABSTRACT}

Background: Information on health disparities between Aboriginal and non-Aboriginal populations is essential for developing public health programs aimed at reducing such disparities. The lack of data on disparities in birth outcomes between Inuit and non-Inuit populations in Canada prompted us to compare birth outcomes in Inuit-inhabited areas with those in the rest of the country and in other rural and northern areas of Canada.

Methods: We conducted a cohort study of all births in Canada during 1990-2000 using linked vital data. We identified 13642 births to residents of Inuit-inhabited areas and 4054489 births to residents of all other areas. The primary outcome measures were preterm birth, stillbirth and infant death.

Results: Compared with the rest of Canada, Inuit-inhabited areas had substantially higher rates of preterm birth (risk ratio [RR] 1.45, 95\% confidence interval [CI] 1.38-1.52), stillbirth (RR 1.68, 95\% Cl 1.38-2.04) and infant death (RR 3.61, $95 \% \mathrm{Cl} 3.17-4.12$ ). The risk ratios and absolute differences in risk for these outcomes changed little over time. Excess mortality was observed for all major causes of infant death, including congenital anomalies (RR 1.64), immaturityrelated conditions (RR 2.96), asphyxia (RR 2.43), sudden infant death syndrome (RR 7.15), infection (RR 8.32) and external causes (RR 7.30). Maternal characteristics accounted for only a small part of the risk disparities. Substantial risk ratios for preterm birth, stillbirth and infant death remained when the comparisons were restricted to other rural or northern areas of Canada.

Interpretation: The Inuit-inhabited areas had much higher rates of preterm birth, stillbirth and infant death compared with the rest of Canada and with other rural and northern areas. There is an urgent need for more effective interventions to improve maternal and infant health in Inuit-inhabited areas.

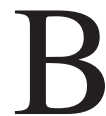
irth outcomes are worse in Aboriginal than in nonAboriginal populations in many developed countries, including the United States, Australia and Canada. ${ }^{1-18}$ Inuit are the smallest Aboriginal group in Canada, with a population of about $45000 .{ }^{19}$ Some regional and community studies have shown that Inuit experience the highest rates of infant mortality in Canada. ${ }^{16-18}$ However, data are lacking at the national level on birth outcomes among Inuit owing to the absence of Aboriginal identifiers on birth registration forms in most provinces.

In Canada, over $80 \%$ of all Inuit reside in one of four vast, sparsely populated regions: the Inuvialuit region of the Northwest Territories, Nunavut, Nunavik (northern Quebec) and Nunatsiavut (northern coast of Labrador) (Figure 1). Taken together, $80 \%$ of the population in those four regions is Inuit, ${ }^{20}$ and $90 \%$ of the births are to Inuit women according to 2006 census data. This creates an opportunity to examine birth outcomes according to maternal place of residence in any of the four Inuit-inhabited areas of Canada. We conducted this study to describe birth outcomes in those areas compared with outcomes in the rest of country and in other rural and northern areas of Canada.

\section{Methods}

\section{Study population}

We conducted a retrospective cohort study using linked data on live births, infant deaths and stillbirths provided by Statistics Canada for all births in Canada from 1990 to $2000(n=4107131)$. We excluded 39000 births $(0.9 \%)$ with missing data on birth weight or gestational age, or with extremely low reported birth weight $(<500 \mathrm{~g})$ or gestational age $(<20$ weeks) because of their borderline viability. Of these excluded births, $281(2.0 \%)$ were in the Inuit-inhabited areas and $38719(0.9 \%)$ were in other areas $(p<0.001)$. Not unexpectedly, infant mortality was high (138 per 1000) among those excluded births. The validity of the linked vital data has been well documented. ${ }^{21}$ We chose the period 1990-2000 because those

From the Department of Obstetrics and Gynecology (Luo, Simonet), Hôpital Sainte-Justine and Université de Montréal, Montréal, Que.; Strategic Research and Analysis, Indian and Northern Affairs Canada (Senécal, Guimond, Penney), Gatineau, Que.; the Department of Sociology (Senécal, Guimond), University of Western Ontario, London, Ont.; the Health Analysis Division, Statistics Canada (Wilkins), Ottawa, Ont.; and the Department of Epidemiology and Community Medicine (Wilkins), University of Ottawa, Ottawa, Ont.

CMAJ 2010. DOI:10.1503/cmaj.082042 
were the most recent years in Statistics Canada's linked data files at the start of our study.

The study was approved by the research ethics board of Hôpital Sainte-Justine, Université de Montréal. We did not seek informed consent from individual participants because the study was based on anonymized linked data.

\section{Geocoding of maternal place of residence}

We determined the maternal place of residence as shown on birth registrations using postal codes or, if postal codes were unavailable, municipal codes assigned from place names. Through geocoding, ${ }^{22}$ we obtained the census subdivision (municipality) code of the maternal place of residence for each birth. Inuit-inhabited areas were defined as any census subdivision whose population was at least 33\% Inuit (by selfreported identity) in the 2001 census. $^{20}$

We defined rural areas using Statistics Canada's definition of rural areas and small towns. ${ }^{23}$ Urban areas referred to census subdivisions in any census metropolitan area or census agglomeration with a population of 10000 or more people. We considered as rural all remaining census subdivisions that were not in any census metropolitan area or census agglomeration. ${ }^{23}$ About $22 \%$ of Canadians live in rural areas. The country can be divided into four geographic areas from north to south: North, North Transition, South Transition and South. ${ }^{24}$ Because all Inuit-inhabited areas are rural and in the northern zones, we did additional analyses in which we restricted comparisons to the rest of rural Canada and to the rest of northern Canada.

\section{Outcome measures}

Our primary outcome measures were preterm birth $(<37$ completed weeks of gestation), stillbirth (fetal death $\geq 20$ weeks' gestation and $\geq 500 \mathrm{~g})$ and infant death $(<365$ days after birth). Other outcomes included small-for-gestationalage (birth weight $<10$ th percentile, based on the Canadian fetal growth standards ${ }^{25}$ ), large-for-gestational-age (birth weight $>90$ th percentile), low-birth-weight $(<2500 \mathrm{~g})$ and high-birth-weight $(>4000 \mathrm{~g})$ births; neonatal death $(<28$ days after birth); postneonatal death (28-364 days after birth); perinatal deaths (stillbirths plus neonatal deaths); and total fetal and infant deaths (stillbirths plus infant deaths).

We investigated causes of death according to the classification of the International Collaborative Effort on Perinatal and Infant Mortality ${ }^{26}$ based on International Classification of Diseases (ICD) codes (ICD-9 codes for deaths in 1990-1999 and ICD-10 codes for deaths in 2000 and 2001). The categories of causes of death included congenital anomalies, immaturity-related conditions, asphyxia, sudden infant death syndrome, infection and external causes. For stillbirths, we analyzed two major causes of death - congenital anomalies and asphyxia - because the numbers of deaths in other categories were small and because the cause of death was unknown or not stated in about a third of stillbirths.

\section{Statistical analysis}

We compiled crude rates of adverse outcomes for births in the Inuit-inhabited areas, the rest of Canada, the rest of rural

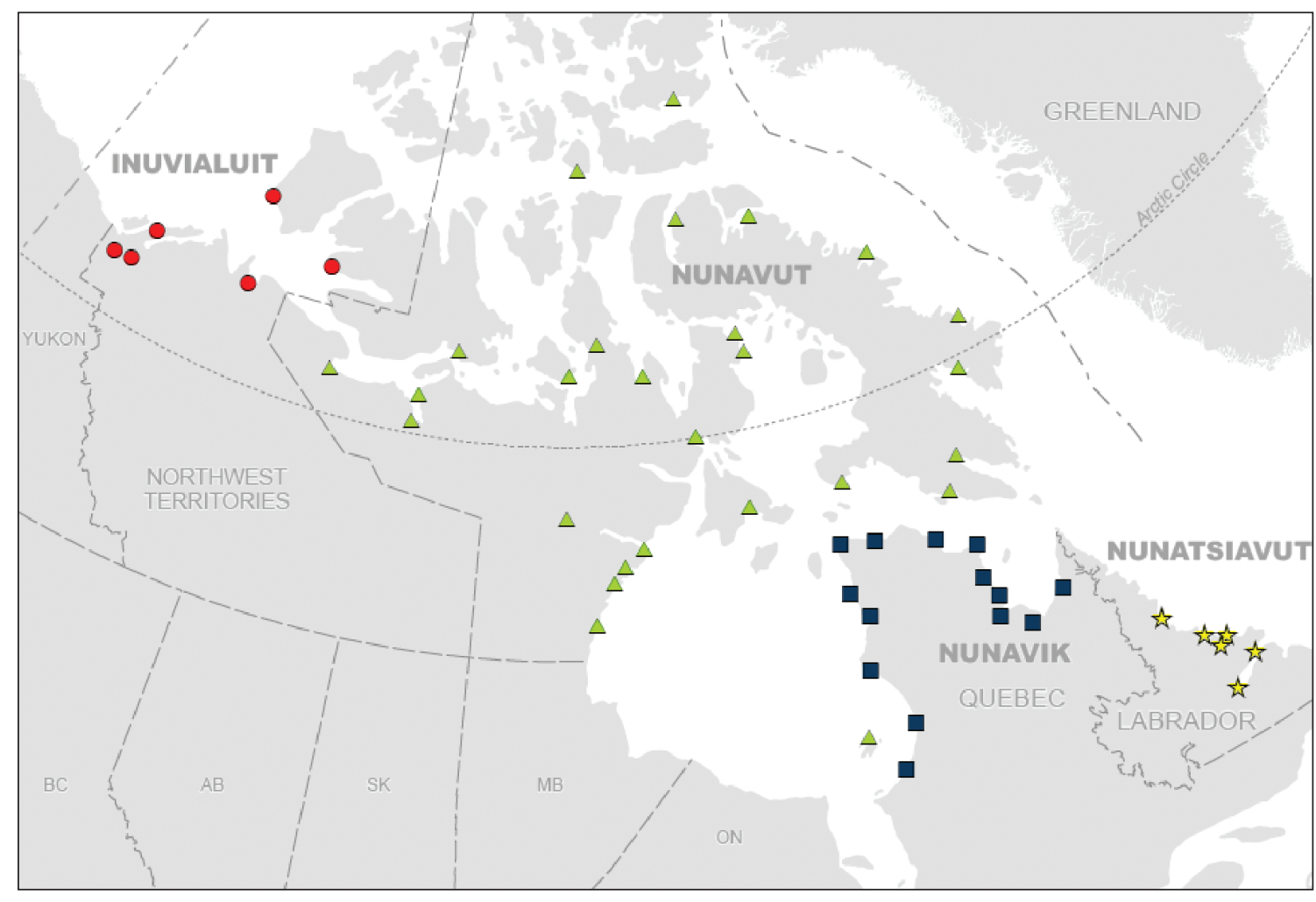

Figure 1: Inuit-inhabited communities in the Inuvialuit (dots), Nunavut (triangles), Nunavik (squares) and Nunatsiavut (stars) regions of Canada. Source: Statistics Canada population data. Base map @ 2002 Government of Canada with permission from Natural Resources Canada. 
Canada and the rest of northern Canada. For preterm, smallfor-gestational-age, large-for-gestational-age, low-birth-weight and high-birth-weight births, we calculated rates per 100 total births (live births plus stillbirths). For fetal and infant deaths combined, perinatal deaths and stillbirths, we calculated rates per 1000 total births. For infant deaths and neonatal deaths, rates were per 1000 live births. We calculated the rate of postneonatal deaths per 1000 neonatal survivors.

We determined absolute risk differences and risk ratios with $95 \%$ confidence intervals to illustrate the magnitude of the disparities. We used the $\chi^{2}$ test to examine the statistical significance of differences across the four Inuit-inhabited areas, and the Cochran-Armitage test to examine the statistical significance of trends over time. We used logistic regression analysis to obtain adjusted odds ratios for assessing whether the elevated risks could be explained by differences in maternal age $(<20,20-29,30-34, \geq 35$ years), parity (primiparous or not), marital status (legally married or not), infant sex and plurality (singleton or multiple birth).

\section{Results}

Of the 4068131 births included in our study, 13642 were to residents of the Inuit-inhabited areas and 4054489 were to residents of all other areas.

Maternal characteristics differed substantially between Inuit-inhabited areas and the rest of Canada. Inuit-inhabited areas had a higher proportion of mothers who were less than 20 years of age ( $22 \%$ v. $6 \%, p<0.001)$, who were not legally married $(71 \%$ v. $29 \%, p<0.001)$ and who were multiparous (70\% v. $57 \%, p<0.001)$. The proportion of male infants was similar (about $51 \%$ in each area, $p=0.47$ ).

Compared with the rest of Canada, Inuit-inhabited areas had higher rates of preterm birth but lower rates of small-forgestational-age births and thus only slightly higher rates of lowbirth-weight births (Table 1). Total fetal and infant mortality in the Inuit-inhabited areas was 2.66 times that in the rest of Canada. Inuit-inhabited areas had substantially higher rates of stillbirth and infant, neonatal and postneonatal death. Excess

Table 1: Number of births, rates, absolute risk differences and risk ratios for birth outcomes in the Inuit-inhabited areas* compared with all other areas of Canada, with other rural areas and with other northern areas of the country, 1990-2000

\begin{tabular}{|c|c|c|c|c|c|c|c|c|c|c|}
\hline \multirow[b]{2}{*}{ Outcome } & \multirow{2}{*}{$\begin{array}{c}\text { Inuit- } \\
\text { inhabited } \\
\text { areas, } \\
N \text { or ratet }\end{array}$} & \multicolumn{3}{|c|}{ All other areas } & \multicolumn{3}{|c|}{ Other rural areas } & \multicolumn{3}{|c|}{ Other northern areas } \\
\hline & & $\begin{array}{l}N \text { or } \\
\text { ratet }\end{array}$ & $\mathrm{RD}$ & $\operatorname{RR}(95 \% \mathrm{Cl})$ & $\begin{array}{l}N \text { or } \\
\text { ratet }\end{array}$ & $\mathrm{RD}$ & $\mathrm{RR}(95 \% \mathrm{Cl})$ & $\begin{array}{l}N \text { or } \\
\text { ratet }\end{array}$ & $\mathrm{RD}$ & $\mathrm{RR}(95 \% \mathrm{Cl})$ \\
\hline \multicolumn{11}{|l|}{ Births } \\
\hline Total & 13642 & 4054489 & & & 829943 & & & 89635 & & \\
\hline Live & 13541 & 4036651 & & & 826475 & & & 89153 & & \\
\hline Preterm & 10.7 & 7.4 & 3.3 & $1.45(1.38-1.52)$ & 6.6 & 4.1 & $1.62(1.54-1.70)$ & 6.9 & 3.8 & $1.56(1.48-1.65)$ \\
\hline $\begin{array}{l}\text { Small for gestational } \\
\text { age }\end{array}$ & 7.1 & 10.5 & -3.4 & $0.67(0.63-0.72)$ & 9.9 & -2.8 & $0.72(0.67-0.76)$ & 8.6 & -1.5 & $0.82(0.77-0.87)$ \\
\hline Low birth weight & 6.7 & 5.9 & -0.8 & $1.13(1.06-1.21)$ & 5.4 & 1.3 & $1.24(1.17-1.32)$ & 5.2 & 1.5 & $1.28(1.20-1.38)$ \\
\hline High birth weight & 13.1 & 12.6 & 0.5 & $1.04(0.99-1.08)$ & 14.2 & -1.1 & $0.92(0.88-0.96)$ & 17.7 & -4.6 & $0.74(0.70-0.77)$ \\
\hline $\begin{array}{l}\text { Large for gestational } \\
\text { age }\end{array}$ & 13.8 & 10.3 & 3.5 & $1.34(1.28-1.39)$ & 11.3 & 2.5 & $1.22(1.17-1.27)$ & 15.1 & -1.3 & $0.91(0.87-0.95)$ \\
\hline \multicolumn{11}{|l|}{ Deaths } \\
\hline $\begin{array}{l}\text { Fetal and infant } \\
\text { death (combined) }\end{array}$ & 23.8 & 9.0 & 14.9 & $2.66(2.39-2.96)$ & 9.5 & 14.3 & $2.52(2.26-2.81)$ & 13.2 & 10.6 & $1.80(1.60-2.06)$ \\
\hline Perinatal death & 13.1 & 7.2 & 5.9 & $1.82(1.57-2.10)$ & 7.2 & 5.9 & $1.82(1.57-2.11)$ & 9.3 & 3.8 & $1.40(1.20-1.65)$ \\
\hline Stillbirth & 7.4 & 4.4 & 3.0 & $1.68(1.38-2.04)$ & 4.2 & 3.2 & $1.77(1.45-2.16)$ & 5.4 & 2.0 & $1.38(1.11-1.70)$ \\
\hline Congenital anomaly & 0.8 & 0.5 & 0.3 & $1.62(0.89-2.93)$ & 0.4 & 0.4 & $1.84(1.01-3.37)$ & 0.6 & 0.2 & $1.42(0.74-2.72)$ \\
\hline Asphyxia & 3.1 & 1.8 & 1.3 & $1.73(1.28-2.34)$ & 1.7 & 1.4 & $1.80(1.32-2.44)$ & 2.0 & 1.1 & $1.56(1.11-2.18)$ \\
\hline Neonatal death & 5.8 & 2.8 & 3.0 & $2.03(1.63-2.54)$ & 3.1 & 2.7 & $1.89(1.51-2.36)$ & 4.0 & 1.8 & $1.44(1.13-1.84)$ \\
\hline Postneonatal death & 10.8 & 1.7 & 9.1 & $6.21(5.27-7.31)$ & 2.3 & 8.5 & $4.91(4.07-6.10)$ & 3.9 & 6.9 & $2.78(2.30-3.37)$ \\
\hline Infant death & 16.5 & 4.6 & 11.9 & $3.61(3.17-4.12)$ & 5.3 & 11.2 & $3.12(2.73-3.57)$ & 7.9 & 8.7 & $2.10(1.81-2.44)$ \\
\hline Congenital anomaly & 2.7 & 1.7 & 1.0 & $1.64(1.19-2.27)$ & 1.9 & 0.8 & $1.41(1.02-1.95)$ & 2.5 & 0.2 & $1.08(0.76-1.53)$ \\
\hline Immaturity-related & 2.7 & 0.9 & 1.8 & $2.96(2.13-4.11)$ & 0.9 & 1.8 & $3.06(2.19-4.27)$ & 1.1 & 1.6 & $2.42(1.65-3.54)$ \\
\hline Asphyxia & 1.0 & 0.4 & 0.6 & $2.43(1.41-4.20)$ & 0.4 & 0.6 & $2.25(1.29-3.91)$ & 0.5 & 0.5 & $1.78(0.97-3.29)$ \\
\hline $\begin{array}{l}\text { Sudden infant } \\
\text { death syndrome }\end{array}$ & 5.2 & 0.7 & 4.5 & $7.15(5.65-9.04)$ & 0.9 & 4.3 & $4.36(3.18-5.99)$ & 1.8 & 3.4 & $2.90(2.20-3.84)$ \\
\hline Infection & 2.3 & 0.3 & 2.0 & $8.32(5.82-11.88)$ & 0.4 & 1.9 & $6.12(4.23-8.85)$ & 0.8 & 1.5 & $2.80(1.84-4.25)$ \\
\hline External cause & 0.9 & 0.1 & 0.8 & $7.30(4.12-12.94)$ & 0.2 & 0.7 & $5.23(2.90-9.43)$ & 0.3 & 0.6 & $3.44(1.71-6.90)$ \\
\hline
\end{tabular}

Note: $\mathrm{Cl}=$ confidence interval, $\mathrm{RD}=$ absolute risk difference, $\mathrm{RR}=$ risk ratio

*All Inuit-inhabited areas are rural and in northern Canada.

tRates are per 100 total births for preterm, small-for-gestational-age, low-birth-weight, large-for-gestational-age and high-birth-weight birth; per 1000 total births for fetal and infant death (combined), perinatal death and stillbirth; per 1000 live births for neonatal death and infant death; and per 1000 neonatal survivors for postneonatal death. 
mortality was observed for all major causes of infant death, including congenital anomalies (risk ratio [RR] 1.64), immaturity-related conditions (RR 2.96), asphyxia (RR 2.43), sudden infant death syndrome (RR 7.15), infection (RR 8.32) and external causes (RR 7.30). The major causes of excess stillbirth were asphyxia (RR 1.73) and congenital anomalies (RR 1.62).

The risk ratios for stillbirth and perinatal, infant and total fetal and infant death changed little when the comparison was restricted to other rural areas of Canada (Table 1). These risks decreased when the comparison was restricted to other northern areas of Canada, but they were still substantial (Table 1). The rate differences for total fetal and infant death per 1000 total births were 14.9 for the comparison of Inuit-inhabited areas and the rest of Canada, 14.3 for the comparison with other rural areas and 10.6 for the comparison with other northern areas.

Across the four Inuit-inhabited regions, the rates of preterm, small-for-gestational-age, low-birth-weight, highbirth-weight and large-for-gestational-age births differed significantly; none of the rates of death differed significantly across the regions (Table 2). Compared with the rest of Canada, all rates of death were significantly higher in each of the four Inuit-inhabited areas $(p<0.001)$.

Overall, there was little change over the three periods (1990-1993, 1994-1997, 1998-2000) in the risk ratios for birth outcomes in the Inuit-inhabited areas compared with the rest of Canada, except that the risk ratios for stillbirth and perinatal death increased noticeably in the last period (Table 3 ). The absolute risk differences changed little over time for total fetal and infant death; they decreased for infant death and increased for stillbirth and perinatal death (Figure 2). There was little change over time in the risk ratios when the comparisons were restricted to other rural or northern areas of Canada.

The crude and adjusted odds ratios for birth outcomes in Inuit-inhabited areas compared with the rest of Canada, with other rural areas and with other northern areas are shown in Figure 3 and Table 4 . The odds ratios for preterm, small-forgestational-age, low-birth-weight, high-birth-weight and large-for-gestational-age births changed little after adjustment for maternal age, parity, marital status, infant sex and plurality in all three comparisons. For most of the mortality indicators, the adjusted odds ratios were smaller than or changed little from the crude values. Adjustment substantially decreased the odds ratios for postneonatal death, infant death overall and infant death due to sudden infant death syndrome, infection and external causes, although these risks remained significantly elevated in the Inuit-inhabited areas. However, odds ratios for stillbirth due to congenital anomalies and asphyxia were no longer significant after adjustment.

\section{Interpretation}

We observed large and persistent disparities in fetal and infant mortality between Inuit-inhabited areas and other areas of Canada. The risks of preterm birth, stillbirth and especially infant death were substantially elevated. Fetal and infant mortality was consistently high across all four Inuit-inhabited

Table 2: Number of births and rates of birth outcomes in the four Inuit-inhabited regions compared with all other areas of Canada, 1990-2000

\begin{tabular}{|c|c|c|c|c|c|c|}
\hline \multirow[b]{2}{*}{ Outcome } & \multicolumn{4}{|c|}{ Inuit-inhabited region; $N$ or rate* } & \multirow{2}{*}{$\begin{array}{l}\text { All other } \\
\text { areas, } \\
N \text { or rate* }\end{array}$} & \multirow{2}{*}{$\begin{array}{c}p \text { value for } \\
\text { differences across } \\
\text { Inuit-inhabited } \\
\text { regionst }\end{array}$} \\
\hline & Inuvialuit & Nunavut & Nunavik & Nunatsiavut & & \\
\hline \multicolumn{7}{|l|}{ Births } \\
\hline Total & 1428 & 7944 & 3180 & 1090 & 4054489 & \\
\hline Live & 1419 & 7885 & 3157 & 1080 & 4036651 & \\
\hline Preterm & 7.9 & 11.3 & 10.7 & 10.6 & 7.4 & 0.003 \\
\hline Small for gestational age & 6.6 & 7.7 & 5.8 & 7.1 & 10.5 & 0.004 \\
\hline Low birth weight & 5.0 & 7.4 & 5.9 & 5.6 & 5.9 & $<0.001$ \\
\hline High birth weight & 16.6 & 11.0 & 14.2 & 20.1 & 12.6 & $<0.001$ \\
\hline Large for gestational age & 14.4 & 12.0 & 15.8 & 19.5 & 10.3 & $<0.001$ \\
\hline \multicolumn{7}{|l|}{ Deaths } \\
\hline $\begin{array}{l}\text { Fetal and infant death } \\
\text { (combined) }\end{array}$ & 19.6 & 23.8 & 25.2 & 25.7 & 9.0 & 0.68 \\
\hline Perinatal death & 10.5 & 13.2 & 14.2 & 12.8 & 7.2 & 0.79 \\
\hline Stillbirth & 6.3 & 7.4 & 7.2 & 9.2 & 4.4 & 0.87 \\
\hline Neonatal death & 4.2 & 5.8 & 7.0 & 3.7 & 2.8 & 0.53 \\
\hline Postneonatal death & 9.2 & 10.7 & 11.2 & 13.0 & 1.7 & 0.83 \\
\hline Infant death & 13.4 & 16.5 & 18.1 & 16.7 & 4.6 & 0.73 \\
\hline
\end{tabular}

*Rates are per 100 total births for preterm, small-for-gestational-age, low-birth-weight, large-for-gestational-age and high-birth-weight birth; per 1000 total births for fetal and infant death (combined), perinatal death and stillbirth; per 1000 live births for neonatal death and infant death; and per 1000 neonatal survivors for postneonatal death.

tFor all outcomes, $p<0.001$ for differences across all five areas (the four Inuit-inhabited areas and all other areas of Canada). 
regions. The risk ratios remained significant and substantial even when the comparisons were restricted to other rural or northern areas. Neither the risk ratios nor the absolute risk differences diminished over time, which indicates a need for more effective interventions to improve maternal and infant health in Inuit-inhabited areas.

Regional and community-based studies have previously documented substantially elevated risks of fetal and infant death among Canadian Inuit. ${ }^{16,18}$ High risk ratios for infant death in Aboriginal compared with non-Aboriginal populations have also been observed in Western Australia (RR 3.0 in 1980-84; RR 4.4 in 1998-2001). ${ }^{6}$ In contrast, risk ratios for infant death in American Indian and Alaskan Native populations compared with white populations were much lower (RR 1.9 in 1989-91; RR 1.7 in 1998-2001). ${ }^{15}$ The rate of infant death in the Inuit-inhabited regions of Canada was 16.5 per 1000 live births during the study period, which almost equaled the rate in all of Canada in $1971 .^{27}$

Even when we restricted the comparisons to other areas of rural or northern Canada, the Inuit-inhabited areas experienced substantially higher rates of stillbirth and infant death. A substantial proportion of the residents of other areas of northern Canada were First Nations, who are known to have higher fetal and infant mortality than non-Aboriginal populations. ${ }^{10,16}$ Consistent with previous findings of disparities in infant mortality between Aboriginal and non-Aboriginal populations, ${ }^{6,9,10,16}$ we observed that the disparity in postneonatal mortality was much larger than that in neonatal mortality. Differences in maternal socio-demographic characteristics may explain in part the disparity in postneonatal mortality, but less so the disparity in stillbirth or neonatal mortality. Programs promoting improved infant care that are targeted at teenaged and single mothers may help to reduce postneonatal mortality.

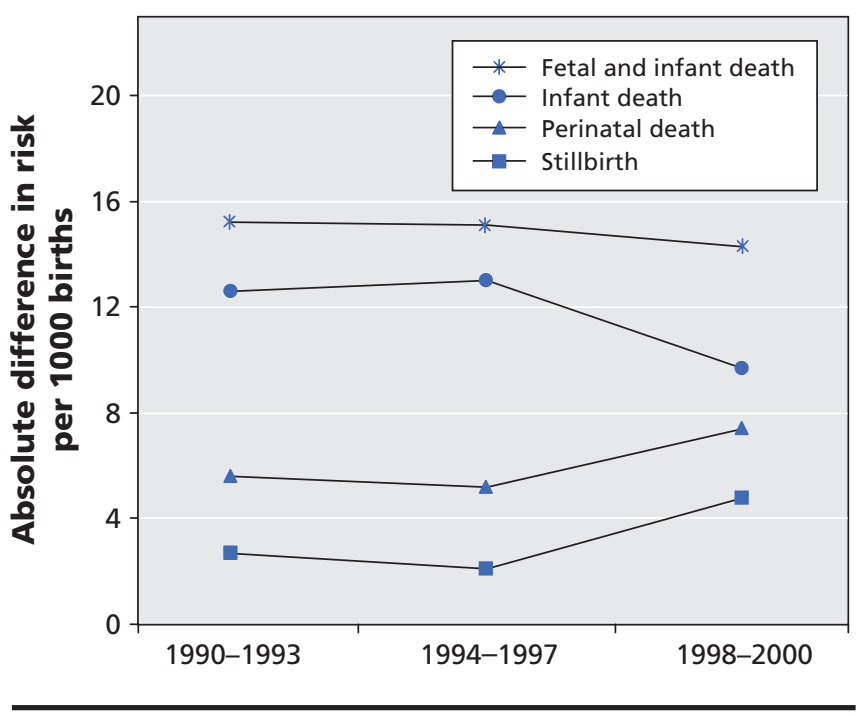

Figure 2: Absolute differences in risk for fetal and infant death in the Inuit-inhabited areas compared with all other areas of Canada, by study period.

Table 3: Number of births, rates and risk ratios for birth outcomes in the Inuit-inhabited areas and all other areas of Canada, by period

\begin{tabular}{|c|c|c|c|c|c|c|c|c|c|}
\hline \multirow[b]{2}{*}{ Outcome } & \multicolumn{3}{|c|}{ 1990-1993 } & \multicolumn{3}{|c|}{ 1994-1997 } & \multicolumn{3}{|c|}{ 1998-2000 } \\
\hline & $\begin{array}{c}\text { Inuit- } \\
\text { inhabited } \\
\text { areas, } \\
N \text { or rate* }\end{array}$ & $\begin{array}{c}\text { All other } \\
\text { areas, } \\
N \text { or rate* }\end{array}$ & $\mathrm{RR}(95 \% \mathrm{Cl})$ & $\begin{array}{c}\text { Inuit- } \\
\text { inhabited } \\
\text { areas, } \\
N \text { or rate* }\end{array}$ & $\begin{array}{c}\text { All other } \\
\text { areas, } \\
N \text { or rate* }\end{array}$ & $\mathrm{RR}(95 \% \mathrm{Cl})$ & $\begin{array}{c}\text { Inuit- } \\
\text { inhabited } \\
\text { areas, } \\
N \text { or rate* }\end{array}$ & $\begin{array}{c}\text { All other } \\
\text { areas, } \\
N \text { or rate* }\end{array}$ & $\mathrm{RR}(95 \% \mathrm{Cl})$ \\
\hline \multicolumn{10}{|l|}{ Births } \\
\hline Total & 5009 & 1572584 & & 5068 & 1474653 & & 3565 & 1007252 & \\
\hline Live & 4973 & 1565461 & & 5035 & 1468170 & & 3533 & 1003020 & \\
\hline Preterm & 10.1 & 6.9 & $1.46(1.34-1.58)$ & 11.0 & 7.8 & $1.40(1.29-1.52)$ & 11.2 & 7.5 & $1.50(1.37-1.65)$ \\
\hline $\begin{array}{l}\text { Small for } \\
\text { gestatinal age }\end{array}$ & 7.4 & 11.2 & $0.67(0.60-0.73)$ & 7.7 & 10.7 & $0.72(0.66-0.80)$ & 5.7 & 9.2 & $0.61(0.54-0.70)$ \\
\hline Low birth weight & 6.0 & 5.8 & $1.03(0.92-1.15)$ & 7.0 & 6.0 & $1.17(1.06-1.29)$ & 7.1 & 5.8 & $1.22(1.09-1.38)$ \\
\hline High birth weight & 13.1 & 12.4 & $1.05(0.98-1.13)$ & 12.7 & 12.3 & $1.04(0.96-1.11)$ & 13.5 & 13.3 & $1.01(0.93-1.10)$ \\
\hline $\begin{array}{l}\text { Large for } \\
\text { gestational age }\end{array}$ & 13.2 & 9.7 & $1.36(1.27-1.46)$ & 13.7 & 10.3 & $1.33(1.24-1.42)$ & 14.7 & 11.2 & $1.31(1.21-1.41)$ \\
\hline \multicolumn{10}{|l|}{ Deaths } \\
\hline $\begin{array}{l}\text { Fetal and infant } \\
\text { death (combined) }\end{array}$ & 24.8 & 9.6 & $2.57(2.16-3.06)$ & 23.9 & 8.8 & $2.70(2.27-3.23)$ & 22.4 & 8.1 & $2.78(2.24-3.46)$ \\
\hline Perinatal death & 13.2 & 7.6 & $1.73(1.31-2.20)$ & 12.4 & 7.2 & $1.72(1.35-2.20)$ & 14.0 & 6.6 & $2.12(1.61-2.79)$ \\
\hline Stillbirth & 7.2 & 4.5 & $1.59(1.14-2.20)$ & 6.5 & 4.4 & $1.48(1.05-2.08)$ & 9.0 & 4.2 & $2.14(1.51-3.02)$ \\
\hline Neonatal death & 6.0 & 3.1 & 1.95 (1.37-2.79) & 6.0 & 2.8 & $2.10(1.47-3.00)$ & 5.1 & 2.4 & $2.09(1.32-3.33)$ \\
\hline $\begin{array}{l}\text { Postneonatal } \\
\text { death }\end{array}$ & 11.7 & 2.1 & $5.71(4.41-7.39)$ & 11.6 & 1.6 & $7.17(5.53-9.29)$ & 8.5 & 1.5 & $5.85(4.08-8.39)$ \\
\hline Infant death & 17.7 & 5.1 & $3.45(2.80-4.24)$ & 17.5 & 4.5 & $3.93(3.19-4.84)$ & 13.6 & 3.9 & $3.50(2.63-4.64)$ \\
\hline
\end{tabular}

Note: $\mathrm{Cl}=$ confidence interval, $\mathrm{RR}=$ risk ratio.

* Rates are per 100 total births for preterm, small-for-gestational-age, low-birth-weight, large-for-gestational-age and high-birth-weight birth; per 1000 total births for fetal and infant death (combined), perinatal death and stillbirth; per 1000 live births for neonatal death and infant death; and per 1000 neonatal survivors for postneonatal death. 
In our comparison of Inuit-inhabited areas and the rest of Canada, the risk ratios for stillbirth and perinatal and infant death changed little over the study period. However, the absolute difference in risk for infant death decreased from 12.6 per 1000 births in 1990-1993 to 9.7 per 1000 in 1998-2000, whereas for stillbirth, it increased from 2.7 to 4.8 per 1000 and for total fetal and infant death, it remained almost stable at about 15 per 1000 . We speculate that there may have been changes in registration practices in the most recent period in the Inuit-inhabited areas: deaths involving newborns at the borderline of viability (birth weight $<500 \mathrm{~g}$ or gestational age $<20$ weeks) may have been more likely to be registered as stillbirths rather than as neonatal deaths, which would have resulted in an artificial surge in the stillbirth rate but a decline in infant mortality. Our results underline the need to examine both fetal and infant mortality when assessing disparities in birth outcomes between Aboriginal and non-Aboriginal populations. Most previous studies have not examined fetal mortality. ${ }^{6,8-10}$

Our finding of a higher rate of preterm births but a lower rate of small-for-gestational-age births in the Inuit-inhabited areas compared with the rest of Canada is similar to that previously noted among Canadian Inuit. ${ }^{16,18}$ Risk ratios for preterm birth (1.45-1.62 for all comparisons), although high, were much lower than the risk ratios for infant deaths caused by immaturity-related conditions (2.42-3.06) and were unaffected by adjustments for maternal characteristics. This indicates a probable lack of access to high-quality neonatal care for highrisk premature babies born to women living in Inuit-inhabited areas. We observed higher rates of large-for-gestational-age births in the Inuit-inhabited areas compared with the rest of



Figure 3: Crude and adjusted odds ratios (ORs) and 95\% confidence intervals (Cls) for birth outcomes in the Inuit-inhabited areas compared with all other areas of Canada, from 1990 to 2000. 
Canada and with other rural areas, but not when we restricted the comparison to other northern areas. The lack of a difference in the last comparison could be explained by the high proportion of First Nations in the rest of northern Canada and the fact that First Nations babies tend to be large at birth. ${ }^{16,28}$

\section{Limitations}

Our results for the Inuit-inhabited areas cannot be taken as results for Inuit women, because about $10 \%$ of the births in the Inuit-inhabited areas were to non-Inuit women, according to data from the 2006 census. Nevertheless, we observed such large disparities in fetal and infant mortality that our conclusions would not have changed even if we had been able to identify Inuit births at the individual level. We had no data on other maternal and medical risk factors that might have mediated or confounded the observed associations. More studies are needed to understand the possible impacts of those factors.

\section{Conclusions and future directions}

Our findings highlight the dire situations of maternal and infant health in Inuit-inhabited areas compared with the rest of Canada and other rural and northern areas of the country. They underline the need for effective interventions to improve those situations. A substantial part of the excess fetal and infant mortality in the Inuit-inhabited areas may be preventable, such as deaths from sudden infant death syndrome, infection and external causes or injuries. Maternal smoking, an important risk factor for preterm birth, sudden infant death syndrome and postnatal infection, ${ }^{29-31}$ is much more prevalent among Inuit women than among other women in Canada. ${ }^{32}$ Programs to promote smoking cessation, awareness of the dangers of environmental tobacco smoke, and breastfeeding among Inuit mothers are strongly recommended. More effective "back to sleep" campaigns (educating mothers to place their babies on their backs for sleeping to avoid crib deaths often associated with sleeping in the prone position) may help to reduce the incidence of sudden infant death syndrome. ${ }^{33-35}$ Investment in improved socio-economic and living conditions may also help to reduce infant mortality, especially postneonatal mortality, ${ }^{36,37}$ because such improvements would probably decrease exposure to various risks in the environment where the child is raised.

The elevated risk of infant death from congenital anomalies in the Inuit-inhabited regions is of particular concern. Inuit are heavy consumers of marine mammals and fish, which results in exposure to environmental contaminants concentrated through

Table 4: Odds ratios for birth outcomes in the Inuit-inhabited areas compared with all other areas of Canada and other rural and northern areas of the country, 1990-2000

\begin{tabular}{|c|c|c|c|c|c|c|}
\hline \multirow[b]{2}{*}{ Outcome } & \multicolumn{2}{|c|}{ All other areas } & \multicolumn{2}{|c|}{ Other rural areas } & \multicolumn{2}{|c|}{ Other northern areas } \\
\hline & $\begin{array}{c}\text { Crude } \\
\text { OR }(95 \% \mathrm{CI})\end{array}$ & $\begin{array}{l}\text { Adjusted* } \\
\text { OR }(95 \% \mathrm{Cl})\end{array}$ & $\begin{array}{c}\text { Crude } \\
\text { OR }(95 \% \mathrm{CI})\end{array}$ & $\begin{array}{l}\text { Adjusted* } \\
\text { OR }(95 \% \mathrm{Cl})\end{array}$ & $\begin{array}{c}\text { Crude } \\
\text { OR }(95 \% \mathrm{Cl})\end{array}$ & $\begin{array}{l}\text { Adjusted* } \\
\text { OR }(95 \% \mathrm{Cl})\end{array}$ \\
\hline \multicolumn{7}{|l|}{ Births } \\
\hline Preterm & $1.50(1.42-1.59)$ & $1.44(1.36-1.52)$ & $1.69(1.60-1.79)$ & $1.58(1.50-1.68)$ & $1.63(1.54-1.73)$ & $1.56(1.47-1.66)$ \\
\hline Small for gestational age & $0.65(0.61-0.69)$ & $0.62(0.58-0.67)$ & $0.69(0.65-0.74)$ & $0.67(0.62-0.71)$ & $0.81(0.75-0.86)$ & $0.81(0.75-0.87)$ \\
\hline Low birth weight & $1.14(1.07-1.22)$ & $1.06(0.99-1.14)$ & $1.26(1.18-1.35)$ & $1.16(1.08-1.25)$ & $1.31(1.21-1.40)$ & $1.25(1.16-1.35)$ \\
\hline High birth weight & $1.04(0.99-1.10)$ & $1.07(1.02-1.13)$ & $0.91(0.86-0.96)$ & $0.94(0.89-0.99)$ & $0.70(0.66-0.73)$ & $0.69(0.65-0.73)$ \\
\hline Large for gestational age & $1.39(1.32-1.46)$ & $1.41(1.34-1.48)$ & $1.25(1.19-1.32)$ & $1.26(1.20-1.32)$ & $0.90(0.85-0.94)$ & $0.88(0.83-0.93)$ \\
\hline \multicolumn{7}{|l|}{ Deaths } \\
\hline $\begin{array}{l}\text { Fetal and infant death } \\
\text { (combined) }\end{array}$ & $2.70(2.42-3.02)$ & $2.39(2.12-2.68)$ & $2.56(2.28-2.86)$ & $2.13(1.90-2.40)$ & $1.82(1.61-2.02)$ & $1.59(1.40-1.81)$ \\
\hline Perinatal death & $1.83(1.58-2.12)$ & $1.81(1.55-2.12)$ & $1.83(1.57-2.12)$ & $1.64(1.40-1.93)$ & $1.41(1.20-1.66)$ & $1.27(1.07-1.51)$ \\
\hline Stillbirth & $1.69(1.39-2.05)$ & $1.89(1.54-2.33)$ & $1.78(1.46-2.17)$ & $1.68(1.35-2.07)$ & $1.38(1.11-1.71)$ & $1.23(0.97-1.55)$ \\
\hline Congenital anomaly & $1.62(0.89-2.93)$ & $1.00(0.52-1.94)$ & $1.85(1.01-3.37)$ & $1.19(0.91-2.35)$ & $1.42(0.74-2.72)$ & $1.00(0.48-2.10)$ \\
\hline Asphyxia & $1.73(1.28-2.34)$ & $1.06(0.69-1.61)$ & $1.80(1.32-2.44)$ & $1.05(0.68-1.61)$ & $1.56(1.11-2.18)$ & $1.17(0.73-1.88)$ \\
\hline Neonatal death & $2.04(1.63-2.55)$ & $1.71(1.36-2.16)$ & $1.89(1.51-2.37)$ & $1.60(1.26-2.03)$ & $1.45(1.13-1.85)$ & $1.32(1.02-1.71)$ \\
\hline Postneonatal death & $6.26(5.31-7.39)$ & $3.64(3.06-4.32)$ & $4.85(4.10-4.75)$ & $3.19(2.67-3.81)$ & $2.80(2.31-3.40)$ & $2.25(1.84-2.76)$ \\
\hline Infant death & $3.66(3.20-4.18)$ & $2.66(2.31-3.05)$ & $3.16(2.76-3.61)$ & $2.40(2.08-2.77)$ & $2.12(1.82-2.45)$ & $1.82(1.55-2.13)$ \\
\hline Congenital anomaly & $1.64(1.19-2.28)$ & $1.53(1.10-2.11)$ & $1.41(1.02-1.96)$ & $1.26(0.91-1.77)$ & $1.08(0.76-1.53)$ & $1.02(0.72-1.46)$ \\
\hline $\begin{array}{l}\text { Immaturity-related } \\
\text { condition }\end{array}$ & $2.96(2.13-4.12)$ & $2.96(2.13-4.11)$ & $3.06(2.19-4.28)$ & $3.06(2.19-4.27)$ & $2.42(1.65-3.55)$ & $2.42(1.65-3.54)$ \\
\hline Asphyxia & $2.43(1.41-4.20)$ & $2.43(1.41-4.22)$ & $2.25(1.29-3.91)$ & $2.33(1.33-4.09)$ & $1.78(0.97-3.29)$ & $1.95(1.03-3.67)$ \\
\hline $\begin{array}{l}\text { Sudden infant death } \\
\text { syndrome }\end{array}$ & 7.18 (5.67-9.09) & $3.17(2.48-4.05)$ & $5.60(4.39-7.15)$ & $3.14(2.43-4.06)$ & $2.91(2.20-3.85)$ & $2.23(1.66-2.99)$ \\
\hline Infection & $8.33(5.88-11.91)$ & $5.68(3.93-8.22)$ & $6.14(4.24-8.88)$ & $4.21(2.86-6.20)$ & $2.80(1.84-4.26)$ & $2.37(1.53-3.68)$ \\
\hline External cause & $7.31(4.12-12.96)$ & $5.30(4.12-8.94)$ & $5.24(2.90-9.44)$ & $4.23(1.90-8.34)$ & $3.44(1.71-6.90)$ & $2.43(1.61-5.90)$ \\
\hline
\end{tabular}

Note: $\mathrm{Cl}=$ confidence interval, $\mathrm{OR}=$ odds ratio.

*Adjusted for maternal age (<20, 20-29, 30-34, $\geq 35$ years), parity (primiparous or not), marital status (legally married or not), infant sex and plurality (singleton or multiple birth). 
the food chain. ${ }^{38}$ Further studies are warranted to assess whether such exposures may be causal. Also, the high prevalence of alcohol abuse among Inuit women ${ }^{39}$ may increase rates of birth defects related to alcohol toxicity. ${ }^{40}$ Programs to reduce alcohol and other substance abuse among Inuit women of child-bearing age may help to prevent such adverse outcomes. The fact that the risk of infant death from congenital anomalies was comparably high in both the Inuit-inhabited areas and the rest of northern Canada suggests that common environmental risks exist in the North. All adjusted odds ratios were close to 1.0 for stillbirths due to congenital anomalies and asphyxia, which indicates that the differences in maternal characteristics could largely explain those risk differences. However, it remains unclear why women of such a distinct demographic profile (more young and unmarried women in the Inuit-inhabited areas than in the other areas studied) have such high risks of stillbirth from congenital anomalies and asphyxia.

This article has been peer reviewed.

\section{Competing interests: None declared.}

Contributors: Zhong-Cheng Luo, Sacha Senécal and Russell Wilkins conceived the study and obtained the research funding. All of the authors contributed to refining the analytic framework and interpreting the results. Zhong-Cheng Luo and Russell Wilkins conducted the analyses. ZhongCheng Luo was responsible for the literature review and for writing the manuscript. All of the authors contributed to revising the article critically for important intellectual content and approved the final version of the manuscript submitted for publication.

Acknowledgement: The authors are grateful to Statistics Canada for providing access to the data.

Funding: This work was supported by a research grant from the Strategic Research and Analysis Directorate of Indian and Northern Affairs Canada. Zhong-Cheng Luo was supported by a Junior Scholar Award from the Fonds de la recherche en santé du Québec and a New Investigator Award from the Canadian Institutes of Health Research (CIHR). Fabienne Simonet was supported by a PhD studentship from the CIHR Strategic Training Initiative in Research in Reproductive Health Science and a research grant (no. 73551) from the CIHR Institute of Aboriginal Peoples' Health.

\section{REFERENCES}

1. Alessandri LM, Chambers HM, Blair EM, et al. Perinatal and postneonatal mortality among indigenous and non-indigenous infants born in Western Australia, 1980-1998. Med J Aust 2001;175:185-9.

2. Alexander GR, Wingate MS, Boulet S. Pregnancy outcomes of American Indians: contrasts among regions and with other ethnic groups. Matern Child Health J 2008;12(Suppl 1):5-11.

3. Decrease in infant mortality and sudden infant death syndrome among Northwest American Indians and Alaskan Natives — Pacific Northwest, 1985-1996. MMWR Morb Mortal Wkly Rep 1999;48:181-4.

4. Baldwin LM, Grossman DC, Casey S, et al. Perinatal and infant health among rural and urban American Indians/Alaska Natives. Am J Public Health 2002;92:1491-7.

5. Bjerregaard P, Misfeldt J. Infant mortality in Greenland: secular trend and regional variation. Arctic Med Res 1992;51:126-35.

6. Freemantle CJ, Read AW, de Klerk NH, et al. Patterns, trends, and increasing disparities in mortality for Aboriginal and non-Aboriginal infants born in Western Australia, 1980-2001: population database study. Lancet 2006;367:1758-66.

7. Freemantle CJ, Read AW, de Klerk NH, et al. Sudden infant death syndrome and unascertainable deaths: trends and disparities among Aboriginal and non-Aboriginal infants born in Western Australia from 1980 to 2001 inclusive. J Paediatr Child Health 2006;42:445-51.

8. Grossman DC, Krieger JW, Sugarman JR, et al. Health status of urban American Indians and Alaska Natives. A population-based study. JAMA 1994;271:845-50.

9. Grossman DC, Baldwin LM, Casey S, et al. Disparities in infant health among American Indians and Alaska Natives in US metropolitan areas. Pediatrics 2002; 109:627-33.

10. Luo ZC, Kierans WJ, Wilkins R, et al. Infant mortality among First Nations versus non-First Nations in British Columbia: temporal trends in rural versus urban areas, 1981-2000. Int J Epidemiol 2004;33:1252-9.
11. MacMillan HL, MacMillan AB, Offord DR, et al. Aboriginal health. CMAJ 1996; 155:1569-78.

12. Martens PJ, Derksen S. A matter of life and death for Manitoba's children: an overview of birth rates and mortality rates. Can J Public Health 2002;93(Suppl 2):S21-6.

13. Muggah E, Way D, Muirhead M, et al. Preterm delivery among Inuit women in the Baffin Region of the Canadian Arctic. Int J Circumpolar Health 2004;63(Suppl 2):242-7.

14. Nakamura RM, King R, Kimball EH, et al. Excess infant mortality in an American Indian population, 1940 to 1990. JAMA 1991;266:2244-8.

15. Tomashek KM, Qin C, Hsia J, et al. Infant mortality trends and differences between American Indian/Alaska Native infants and white infants in the United States, 1989-1991 and 1998-2000. Am J Public Health 2006;96:2222-7.

16. Luo ZC, Wilkins R, Platt RW, et al. Risks of adverse pregnancy outcomes among Inuit and North American Indian women in Quebec, 1985-97. Paediatr Perinat Epidemiol 2004; 18:40-50.

17. Macaulay A, Orr P, Macdonald S, et al. Mortality in the Kivalliq Region of Nunavut, 1987-1996. Int J Circumpolar Health 2004;63(Suppl 2):80-5.

18. Pageau M, Ferland M, Déry S. Our Children - health status of children aged 0-5 years in Nunavik. Kuujjuaq (Nunavik): Nunavik Regional Board of Health and Social Services; 2003.

19. Aboriginal peoples of Canada: a demographic profile [2001 census: analysis series]. Ottawa (ON): Statistics Canada; 2003. Cat. no. 96F0030XIE2001007. Available: www12.statcan.ca/english/census01/products/analytic/companion/abor /pdf/96F0030XIE2001007.pdf (accessed 2009 Sept. 29).

20. Wilkins R, Uppal S, Finès P, et al. Life expectancy in the Inuit-inhabited areas of Canada, 1989 to 2003. Health Rep 2008;19:7-19.

21. Fair M, Cyr M, Allen AC, et al. An assessment of the validity of a computer system for probabilistic record linkage of birth and infant death records in Canada. The Fetal and Infant Health Study Group. Chronic Dis Can 2000;21:8-13.

22. Wilkins R. PCCF + version 4J user's guide. Automated geographic coding based on the Statistics Canada postal code conversion files, including postal codes to September 2006. Ottawa (ON): Statistics Canada; 2007. Cat. no. 82F0086-XDB.

23. du Plessis V, Beshiri R, Bollman RD, et al. Definitions of rural. Rural and Small Town Canada Analysis Bulletin 2001;3:1-16. Cat. no. 21-006-XIE.

24. McNiven C, Puderer H. Delineation of Canada's North: an examination of the North-South relationship in Canada [geography working paper series no. 2000-3]. Ottawa (ON): Statistics Canada; 2000. Cat. no. 92F0138MPE.

25. Kramer MS, Platt RW, Wen SW, et al.; Fetal/Infant Health Study Group of the Canadian Perinatal Surveillance System. A new and improved population-based Canadian reference for birth weight for gestational age. Pediatrics 2001;108:E35.

26. Cole S, Hartford RB, Bergsjo P, et al. International collaborative effort (ICE) on birth weight, plurality, perinatal, and infant mortality. III: A method of grouping underlying causes of infant death to aid international comparisons. Acta Obstet Gynecol Scand 1989;68:113-7.

27. Wadhera S, Strachan J. Selected infant mortality and related statistics, Canada, 1921-1990. Ottawa (ON): Statistics Canada; 1993. Cat. no. 82-549.

28. Rodrigues S, Robinson EJ, Kramer MS, et al. High rates of infant macrosomia: a comparison of a Canadian native and a non-native population. J Nutr 2000;130:806-12

29. Shea AK, Steiner M. Cigarette smoking during pregnancy. Nicotine Tob Res 2008; 10:267-78.

30. Fleming P, Blair PS. Sudden infant death syndrome and parental smoking. Early Hum Dev 2007;83:721-5.

31. Jeppesen DL, Nielsen SD, Ersboll AK, et al. Maternal smoking during pregnancy increases the risk of postnatal infections in preterm neonates. Neonatology 2008; 94:75-8.

32. Reading J, Allard Y. The tobacco report. In: First Nations and Inuit Regional Health Survey. Ottawa (ON): First Nations and Inuit Regional Health Steering Committee; 1999. p. 87-135.

33. Ponsonby AL, Dwyer T, Cochrane J. Population trends in sudden infant death syndrome. Semin Perinatol 2002;26:296-305.

34. Henderson-Smart DJ, Ponsonby AL, Murphy E. Reducing the risk of sudden infant death syndrome: a review of the scientific literature. J Paediatr Child Health 1998;34:213-9.

35. Dwyer T, Ponsonby AL. Sudden infant death syndrome: after the "back to sleep" campaign. BMJ 1996;313:180-1

36. Singh GK, Kogan MD. Persistent socioeconomic disparities in infant, neonatal, and postneonatal mortality rates in the United States, 1969-2001. Pediatrics 2007 ; 119:e928-39.

37. Arntzen A, Nybo Andersen AM. Social determinants for infant mortality in the Nordic countries, 1980-2001. Scand J Public Health 2004;32:381-9.

38. Muckle G, Ayotte P, Dewailly E, et al. Determinants of polychlorinated biphenyls and methylmercury exposure in Inuit women of childbearing age. Environ Health Perspect 2001;109:957-63.

39. Healey GK, Meadows LM. Inuit women's health in Nunavut, Canada: a review of the literature. Int J Circumpolar Health 2007;66:199-214.

40. Calhoun F, Warren K. Fetal alcohol syndrome: historical perspectives. Neurosci Biobehav Rev 2007;31:168-71

Correspondence to: Dr. Zhong-Cheng Luo, Department of

Obstetrics and Gynecology, Sainte-Justine Hospital,

3175 Côte-Sainte-Catherine, Montréal QC H3T 1C5;

zhong-cheng.luo@recherche-ste-justine.qc.ca 